\title{
Modelling, simulation and comparison of phase change material storage based direct and indirect solar organic Rankine cycle systems
}

\author{
Jahan Zeb Alvi ${ }^{1}$, Yongqiang Feng ${ }^{1 *}$, Qian Wang ${ }^{1 * *}$, Muhammad Imran ${ }^{2}$, Junaid Alvi ${ }^{3}$
}

\author{
${ }^{1}$ School of Energy and Power Engineering, Jiangsu University, 301 Xuefu Road, Zhenjiang, China \\ ${ }^{2}$ Mechanical Engineering \& Design, School of Engineering and Applied Science, Aston University, Aston \\ Triangle, B4 7ET, Birmingham, United Kingdom \\ ${ }^{3}$ Key Laboratory of Efficient Utilization of Low and Medium Grade Energy, MOE, School of Mechanical \\ Engineering, Tianjin University, Tianjin 300072, China \\ *Corresponding author: Dr. Yongqiang Feng, Prof. Qian Wang \\ Email ID: hitfengyq@gmail.com,qwang@ujs.edu.cn
}

Abstract

The thermodynamic performance of a novel direct solar organic Rankine cycle system and conventional indirect solar organic Rankine cycle system is compared in this study. The working fluid is vaporized directly in the solar collectors in direct solar organic Rankine cycle system while heat transfer fluid is used to vaporize the working in indirect solar organic Rankine cycle system. The evacuated flat plate collectors array covering a total aperture area of $150 \mathrm{~m}^{2}$ is employed as a heat source and a phase change material tank having a surface area of $25.82 \mathrm{~m}^{2}$ is used as thermal storage for both configurations. R245fa and water are chosen as heat transfer fluids for direct and indirect solar organic Rankine cycle systems, respectively. However, R245fa is used as a working fluid for both configurations. The performance of both configurations is compared by carrying out weekly, monthly and annual dynamic simulations in MATLAB by using hourly weather data of Islamabad, Pakistan. The direct solar organic Rankine cycle system outperforms the indirect solar organic Rankine cycle system in terms of thermal efficiency and net power. The annual system efficiency and an annual average net power of the direct solar organic Rankine cycle system are $71.96 \%$ and $64.38 \%$ higher than indirect solar organic Rankine cycle system respectively. However, average annual heat stored by phase change material during charging mode of indirect solar organic Rankine cycle system is $4.24 \mathrm{MJ}$ more than direct solar organic Rankine cycle system. Conversely, direct solar organic Rankine cycle system has provided annual daily average power of $33.80 \mathrm{~kW}$ extra to heat transfer fluid during the discharging mode of phase change material storage. Furthermore, with phase change material storage, the capacity factor is increased by $17 \%$ and $21.71 \%$ on annual basis for direct and indirect solar organic Rankine cycle systems, respectively.

Keywords: Organic Rankine Cycle; Direct and Indirect solar ORC system; Phase Change Material; Capacity Factor; Thermodynamic, Comparison 


\section{Introduction}

37 Solar energy has emerged as one of the most rapidly growing renewable sources of electricity. It has a minimum time of replenishment and maximum capacity among all available energy resources [1]. Furthermore, it is an attractive option for coupling with a low-medium temperature organic Rankine cycle (ORC) system. A temperature of $100^{\circ} \mathrm{C}$ or slightly higher is enough to run a solar ORC system. Hence, these solar ORC systems are able to work efficiently within a temperature range of 100 to 150 ${ }^{\circ} \mathrm{C}$. They are beneficial in terms of power, all the way down to small unit sizes, low technical demand in heat storage, co-generation close to the usage point and suitability in regions with less direct solar radiation resources.

To date, most of the studies investigated solar ORC systems use heat transfer fluid (HTF) to transfer energy from collectors to the organic fluid [2-5]. Heat transfer irreversibility largely occurs in the evaporator as explained by Jing et al. [6]. Furthermore, investment cost also increases while using HTF. Extra power is required for the pumping of HTF that can decrease the system's net power output specifically for small-scale solar ORC systems. The direct solar organic Rankine cycle system (DSOS) is one in which the evaporator is replaced with the solar collectors. Hence, all of the aforementioned problems can be resolved by adopting the novel DSOS.

To date, the solar ORC system with direct vapor generation (DVG) is studied by different researchers. Few have conducted experimental work $[7,8]$ while others have done theoretical studies $[6,9,10]$. All of them focused on working fluid selection and performance of the system. This kind of system is found to be promising. In DVG solar ORC system vapor is generated directly in the collectors, the working fluid influences not only the heat to power conversion but also the solar energy collection. Jing et al. [6] explained heat transfer irreversibility largely occurs in the evaporator. Moreover, they found $10 \%$ relative increment in overall electricity efficiency of DVG based solar ORC over conventional solar ORC system at solar radiation of $1000 \mathrm{~W} / \mathrm{m}^{2}$. Furthermore, extra power is required for the pumping of HTF in conventional solar ORC that can decrease the system's net power output and overall system efficiency specifically for small-scale solar ORC systems. Freeman et al. [23] calculated that almost $58 \%$ of the exergy loss occurs in the evaporator. The thermal energy storage is a core component in the development of a solar power system. Thermal energy storage for solar thermal applications can be divided into Latent Heat Storage (LHS) and Sensible Heat Storages (SHS) [11]. Phase Change Materials (PCMs) lies into the LHS group and are one of the promising technology for the development of efficient thermal storage. Moreover, 5-14 times additional energy per volume can be stored by using PCM as compared to sensible-heat storage materials [12]. PCM is also advantageous compared with SHS systems because the process of phase 
change is nearly isothermal for pure substances, and takes place over a finite temperature range for composite materials $[13,14]$. In contrast, past research had shown some disadvantages of PCM related to low thermal conductivity which results in lower charging and discharging rates [15]. PCMs are classified into three different transition phases such as liquid to solid, solid to gas and solid to liquid. The solid-liquid transition can be further subdivided into organic, inorganic and eutectics $[12,16]$. The selection of PCM to make the best latent heat storage system is critical for the specific application since the operating conditions are widely variable. The melting point temperature is a key parameter in the selection process of PCM. An overview of the PCM properties and related applications are studied by Agyenim et al. [14]. The applications are subdivided into low temperature $\left(1-65^{\circ} \mathrm{C}\right)$, medium temperature $\left(80-120^{\circ} \mathrm{C}\right)$ and high temperature $\left(>150^{\circ} \mathrm{C}\right)$. Medium temperature range PCMs are suitable for solar ORC applications.

Previously, researchers have proposed and analyzed different configurations of solar ORC systems. However, few of them have focused on integrating the systems with heat storage. Li et al. [17] analyzed solar organic Rankine cycle with thermal energy storage. A dynamic model of the solar ORC system was developed. The effect of storage capacity, solar fluctuation and evaporation temperature on the solar ORC system were evaluated. It was concluded that a proper thermal energy storage capacity should be selected in order to cater the solar fluctuations of a given area. Wang et al. [3] investigated the off-design performance of the solar ORC system with the compound parabolic collector and sensible thermal storage unit. The system performance was observed under time-varying conditions and changing ambient temperature. The system could obtain maximum exergy efficiency in December while maximum power output in June. Freeman et al. [18] had studied domestic-scale distributed solar combined heat and power system consisting of an organic Rankine cycle for the UK climate. The system comprised of $15 \mathrm{~m}^{2}$ solar collectors, $1 \mathrm{~m}^{3}$ thermo-chemical storage, and ORC engine. Two staged solar collectors were considered. It was found that the proposed system could meet $32 \%$ electricity demands of a UK home. The author suggested that future studies will be focused on providing a proper solution of a finite-sized thermal storage system. Moreover, the effectiveness of the storage system will be assessed for load profile matching over seasonal time-scales. Wang et al. [19] developed a mathematical model to simulate the solar ORC system under steady-state. It was concluded that by employing a heat storage unit into the system, uninterrupted and steady operation of the solar-driven regenerative organic Rankine cycle could be achieved over a long period of time.

Pantaleo et al. [20,21] carried out two different studies on ORC coupled with heat storage. In the first study, the heat was recovered from exhaust gasses of gas turbine via thermal energy storage. Two molten salts storage tanks of (one cold at $200{ }^{\circ} \mathrm{C}$ and one hot at $370{ }^{\circ} \mathrm{C}$ ) and three different plant consequently two thermal energy storage sizes. The thermodynamic performance indicated higher global energy conversion efficiencies while using CSP integration. The second study was focused on 
thermodynamic modelling and chosen two different CSP sizes, storage levels, and operation modes. Two molten salt storage tanks were considered which provided the 4.8-18 MWh energy storage. The plant capacity factor was increased and operating hours increased from 5500-6000 to $8000 \mathrm{~h}$ per year. The integration of ORC with the PCM storage unit has gained attention in the recent past. Gang et al. presented two different configurations $[22,23]$ of the solar ORC system with PCM storage unit. The first study was focused on the comparison of a regenerative ORC with the solo cycle. The system consists of non-tracking solar collectors and ORC engine integrated with a PCM storage tank. The research was focused on the effect of the regenerative cycle on system efficiency and collector efficiency. However, the second study was focused on the arrangement of the two-stage solar collectors. Flat plate collectors with corresponding PCM storage were used for preheating. Compound parabolic concentrators with corresponding PCM storage were used to achieve a higher temperature. Furthermore, collector efficiency and overall cycle efficiency were calculated.

Freeman et al. [24] proposed different thermal energy solutions. Authors applied various combinations of PCMs storage, water storage and solar collectors in a small-scale solar organic Rankine cycle combined heat and power system. Their performance was evaluated for UK and Cyprus climates, respectively. Furthermore, PCMs resulted in a $20 \%$ higher total daily electrical output per unit storage volume as compared to water storage.

Marcello et al. [25] analyzed and compared different PCMs coupled with the ORC system. It was found that the amount of energy stored and the thermal efficiency of the system increased with increasing heat source temperature. Conclusively, it was observed that the amount of energy stored by PCM increased dramatically by using a metal foam. This happened due to the higher thermal conductivity of the foam which resulted in the faster melting process. Manfrida et al. [26] and Sagar et al. [27] integrated PCM storage with solar ORC system. Their studies were focused on developing a mathematical model of PCM storage. Then dynamic simulations of overall systems were carried out for seven and ten days, under time-varying weather conditions (solar radiation, ambient temperature), for first and second study respectively. In case of first study, the model gave time-dependent HTF temperature profile of PCM storage tank outlet. It was then applied to solar ORC system. Weekly average energy efficiency achieved by the PCM storage was $83 \%$ during charging mode and $93 \%$ during discharging mode, respectively. Two different diameters and lengths of PCM storage tank were selected in the second study. It was found that smaller diameter and longer length showed the overall better performance of solar ORC system. In contrast, the pressure drop was significantly high for aforementioned system.

However, previous studies mainly focused on the design and short-time simulations. Detailed modeling and simulation of integrated direct solar organic Rankine cycle system and direct solar organic Rankine cycle system (ISOS) for a whole year had not been reported yet. The novelty of this work lies in the thermodynamic performance assessment and comparison of the performance of DSOS and ISOS based 
on the thermodynamic model. The contribution includes

- Development and validation of the 1-dimensional PCM model for integrated solar ORC system. Temperature profiles of both HTF and PCM are demonstrated and compared for the first time under time-varying weather conditions.

- The weekly, monthly and annual dynamic simulations of the integrated solar ORC system in relation to the charging and discharging characteristics of the PCM storage system. Furthermore, increment in the capacity factor of both configurations by using PCM storage is also analyzed and compared for the first time.

- Thermodynamic performance and comparative assessment of DSOS and ISOS based on system efficiencies and net power output.

The present study is divided into five sections. Section 1 of the paper provides an overview of the current research status in the area of solar organic Rankine cycle (ORC) system with a focus on novelty and originality of the present work. The layout, working principle, and control of the integrated solar ORC system presented in Section 2. The modelling and simulation approach is described in detail in Section 3. The results and discussion of the DSOS and ISOS are provided in Section 4. Finally, the concluding remarks are added in $\underline{\text { Section } 5}$ of the paper.

\section{System configurations and control}

The schematic diagrams of the DSOS and ISOS are shown in Figure 1 and Figure 2, respectively. Present work has been carried out to compare the performance of both configurations on the basis of hourly weather data. Both configurations are comprised of evacuated flat plate collectors (EFPCs), phase change material storage tank and basic ORC plant (evaporator, expander, condenser, and pump) coupled with a generator. PCM storage works in two operating modes (charging mode $\&$ discharging mode). In the case of DSOS, solar collectors work as an evaporator during charging mode as shown in Figure 1. However, during the discharging mode, the PCM storage tank works as an evaporator. One variable flow organic fluid flow pump namely $\mathrm{P}_{1}$ is employed to regulate fluid flow in the system. HTF is replaced by organic fluid in this system. Moreover, R245fa is used as a working fluid.

In the case of ISOS, water works as HTF in the solar loop while R245fa is used as a working fluid ORC loop as shown in Figure 2. Moreover, two variable flow pumps entitled $\mathrm{P}_{1}$ and $\mathrm{P}_{2}$ are employed to control the flow of HTF \& working fluid in solar and ORC loop respectively. Five control valves are also used to properly regulate the flow of fluid in both configurations. The valves open and close based on the operation and control conditions, which are discussed in detail in the section below. Both configurations integrated with PCM storage are simulated in MATLAB programming environment under time-varying solar radiation conditions. 


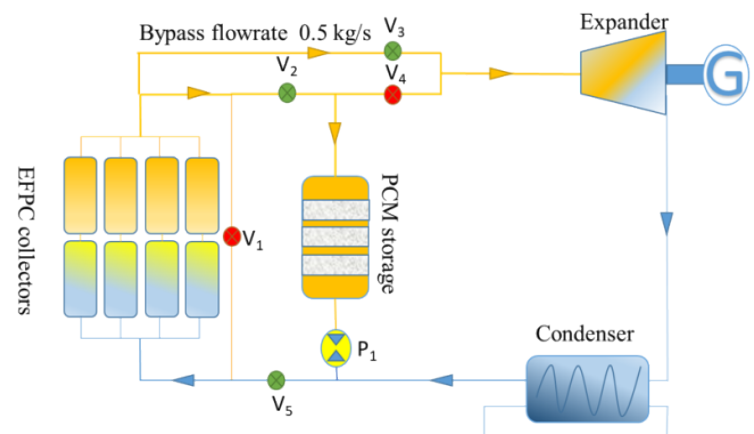

(a)

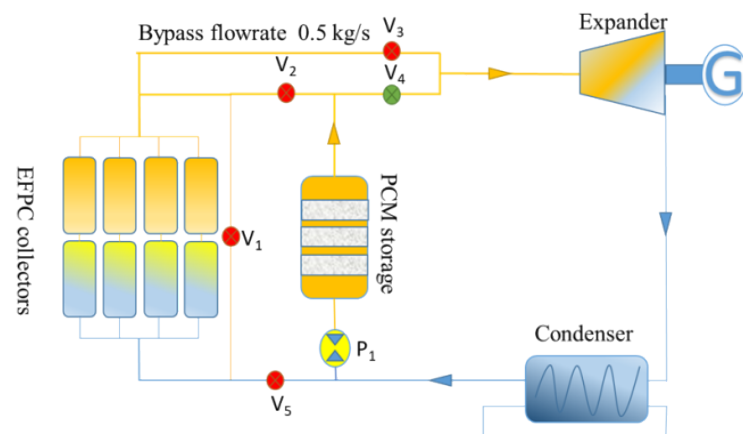

(b)

Figure 1: Layout diagram of direct solar organic Rankine cycle system (DSOS) during (a) charging mode and (b) discharging mode

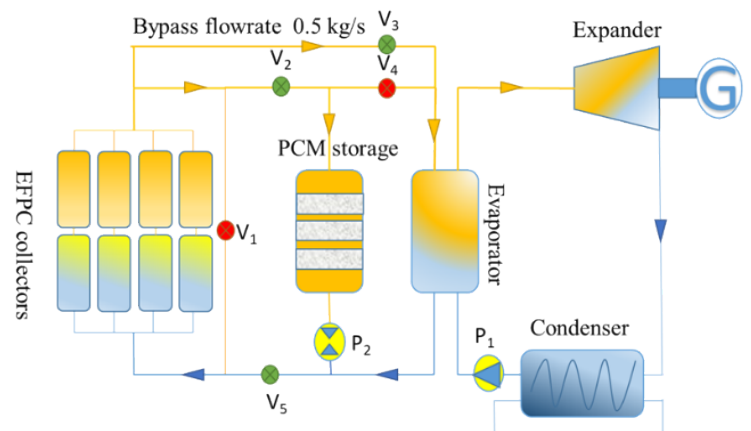

(a)

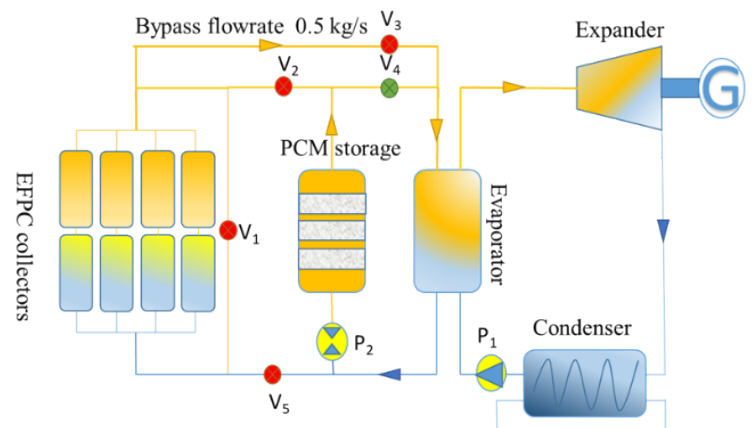

(b)

Figure 2: Layout diagram of indirect solar organic Rankine cycle system (ISOS) during (a) charging mode and (b) discharging mode

Hourly based climatic data of Islamabad-Pakistan has been used for the current study. Typical meteorological year (TMY) data of Islamabad is obtained by using Meteonorm software [28]. Islamabad represents cold winter and very hot and hot-humid summer. The monthly average ambient temperature along with the solar radiation falling on the solar collector surface for the whole year is shown in Figure 3. It can be observed that June is the hottest month with the maximum amount of solar radiation and maximum ambient temperature while January is the coldest month of the year along with low solar radiation and minimum ambient temperature. The first week of January and the second week of June are considered to be the coldest and hottest weeks of the whole year, respectively. 


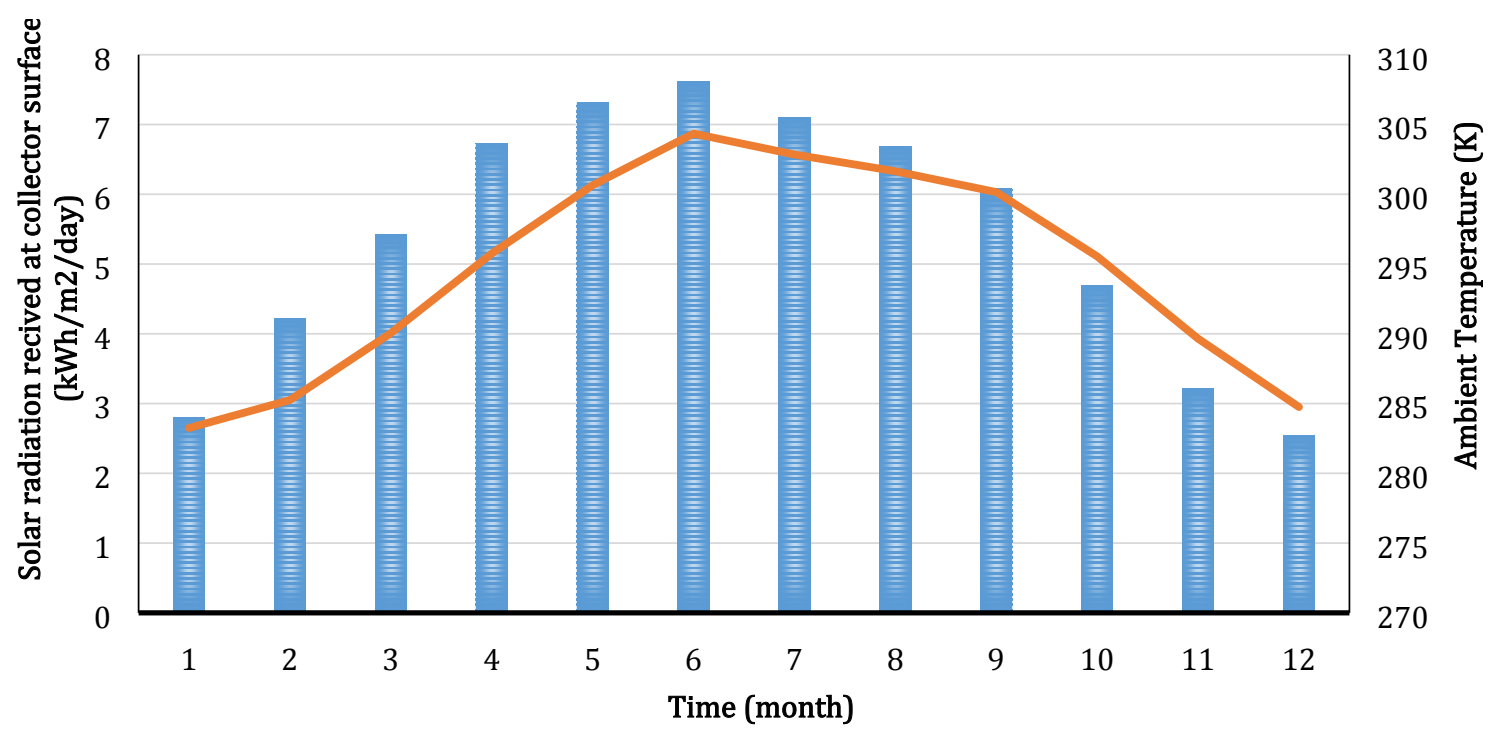

189

\section{Figure 3: Climatic data of Islamabad-Pakistan (daily average monthly)}

To apply the desired logical control system, every component for both configurations is controlled and turned on and off by logical functions depending on several simulation parameters. The values of TMY data of the Islamabad is imported in MATLAB from the metronome software. Both configurations have been evaluated at the same operation and boundary conditions. It is assumed that the system starts working when the solar radiation received at the surface of the collector goes above $400 \mathrm{~W} / \mathrm{m}^{2}$. On the contrary, the system stops or undergoes to discharging mode.

There are two modes of operation of the storage system namely charging and discharging mode. The initial temperature of PCM is assumed to be $373.15 \mathrm{~K}$. This shows that PCM is not charged and in the solid phase at the beginning of the simulation process. Five control valves are employed in both configurations which are opened and closed depending upon the mode of operation. During charging mode, valves V2, V3 and V5 are opened while V1 and V4 remain close. In contrast, during the discharging mode, V4 is opened while the rest of the valves remains close. The heat storage system is designed to work at melting point temperature of the PCM. It means that major part of the energy is released or absorbed at the melting point of PCM.

The maximum temperature at the outlet of collector array is selected to be $390 \mathrm{~K}$ that is slightly higher than the PCM melting point temperature. In this regard, when the collector outlet temperature rises above the limit imposed, V1 is opened and the rest of valves are closed and the HTF mass flow rate is increased by $10 \%$ at every iteration until it reaches below the limit imposed. To avoid the supercritical condition, Initial temperature of HTF mass flow rate during charging mode is selected to be $3 \mathrm{~kg} / \mathrm{s}$ and it increases with increment in collector outlet temperature. However, to achieve consistent power generation, HTF bypass mass flow rate is kept at a constant rate of $0.5 \mathrm{~kg} / \mathrm{s}$ in both charging and discharging mode. The discharging limit of the storage tank is maintained to $370 \mathrm{~K}$, which means that the system is allowed to discharge the storage in sensible heat region. 


\section{Thermodynamic modelling}

\subsection{Solar radiation}

Solar radiation received by the sloped surface of the solar collectors is calculated by [29].

$$
I_{t}=\left(I_{b}+I_{d} \frac{I_{b}}{I_{h}}\right) R_{b}+I_{d}\left(1-\frac{I_{b}}{I_{h}}\right)\left(\frac{1+\cos \beta}{2}\right)\left(1+\sqrt{\frac{I_{b}}{I_{h}}} \operatorname{Sin}^{3}\left(\frac{\beta}{2}\right)\right)+I_{h} \rho_{g}\left(\frac{1-\cos \beta}{2}\right)
$$

218

\subsection{Solar collectors}

For the solar collector's field, evacuated flat plate collectors are selected. Due to vacuum inside the collector, this type of collector is highly efficient at high temperatures up to $200^{\circ} \mathrm{C}$. Moreover, they are non-tracking, non-concentrating collectors. Therefore, they do utilize both beam and diffused radiation [30]. The efficiency of the solar collector is calculated as a function of collector inlet temperature, the ambient air temperature and total solar radiation received at collector surface.

$$
\eta_{c l}=a_{0}-a_{1} \frac{\left(T_{i}-T_{a m b}\right)}{I_{t}}-a_{2} \frac{\left(T_{i}-T_{a m b}\right)^{2}}{I_{t}}
$$

Where $a_{0}, a_{1}$ and $a_{2}$ are the optical efficiency of the collector, linear heat loss coefficient, and quadratic heat loss coefficient, respectively. A total number of solar collectors were assumed to be 75 in collector array and each solar collector has a size of $2 \mathrm{~m}^{2}$. Amount of energy received by the solar collector's array is computed by:

$$
q_{c l}=\eta_{c l} \times I_{t} \times n \times A_{c l}
$$

Furthermore, the temperature at the outlet of the solar collector array is calculated by

$$
T_{o}=T_{i}+\left(\frac{q_{c l}}{\left(m_{f} C_{p}\right)}\right)
$$

\subsection{Phase change material storage}

Figure 4 shows a typical configuration of the PCM storage tank. A cylindrical shape tank completely filled with PCM is considered. Moreover, it has a coiled shape pipe containing HTF passes through the tank. The walls of the PCM storage tank are assumed to be adiabatic.

The tank operates in charging and discharging mode depending upon operation and boundary conditions. During charging mode, the heat is transferred from HTF to the PCM. The PCM temperature rises from solid-phase until it reaches the melting point temperature. After that, the temperature of PCM 
remains constant during the melting process.

243 After completion of the melting phase during which all of the PCM changes into the liquid phase, the temperature of the liquid PCM further rises up to the limit imposed by HTF. However, during a discharging phase, thermal energy stored by liquid PCM is extracted by cold HTF [26]. The well-known enthalpy method is used to solve the governing equations for HTF and PCM as shown in equation (5) [31][32]. In order to determine the heat transfer in PCM while solving the enthalpy method few assumptions are made as follows:

- Conductive heat transfer is considered to be the dominant mechanism.

- Only One-dimensional heat transfer is contemplated.

- The thermos-physical properties of PCM remain constant for each state.

- Natural convection is neglected in this model which may occur due to the density difference in the PCM [33].

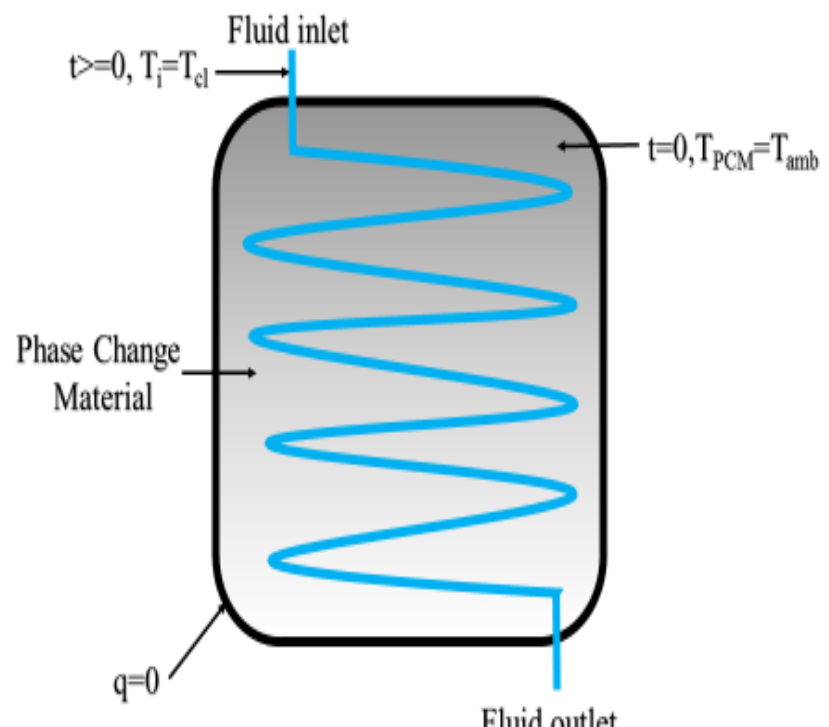

Figure 4: Layout diagram of PCM storage Tank

$$
\rho \frac{\partial H}{\partial t}=\kappa_{p c m} \frac{\partial^{2} T_{p c m}}{\partial y^{2}}
$$

257 Where " $\mathrm{H}$ " is the total volumetric enthalpy, which consists of both the latent heat and the sensible heat of PCM at a given temperature. Therefore, the total volumetric enthalpy of PCM at any given temperature is calculated using the following relation:

$$
H=\int_{T_{m}}^{T} \rho_{p c m} C_{p c m} \Delta T_{p c m}+\rho_{p c m} L F(\lambda)
$$

In the above formulation equation (6), the latent heat of the PCM is related to the liquid fraction of the 
PCM "LF". To compute the latent heat of the PCM, the liquid fraction LF needs to be defined that is calculated as given by the Equation (7)

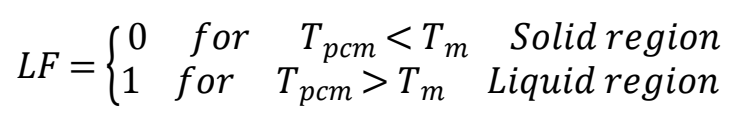

From equation (6) and (7) enthalpy of PCM can be calculated as:

268

$$
H=\left\{\begin{array}{llll}
\rho_{p c m} C_{p c m}\left(T_{p c m}-T_{m}\right) & \text { for } & T_{p c m}<T_{m} & \text { Solid region } \\
\rho_{p c m} C_{p c m}\left(T_{p c m}-T_{m}\right)+\lambda \rho_{p c m} & \text { for } & T_{p c m}>T_{m} & \text { Liquid region }
\end{array}\right.
$$

269

270

271

272

273

274

The above correlation depicts, if the temperature of PCM is less than its melting point temperature, it only contains sensible heat. Conversely, if the temperature of PCM is more than or equal to its melting point temperature, total volumetric enthalpy is the combination of latent heat and sensible heat. The temperature of the PCM " $\mathrm{T}_{\mathrm{pcm}}$ " is further derived from the volumetric enthalpy of the PCM as follows:

$$
T_{p c m}=\left\{\begin{array}{lcc}
T_{m}+\frac{H}{\rho_{p c m} \cdot C_{p c m}} & \text { for } & H<0 \\
T_{m} & \text { for } & 0<H<\rho_{p c m} \cdot \lambda \\
T_{m}+\frac{H-\left(\rho_{p c m} \cdot \lambda\right)}{\rho_{p c m} \cdot C_{p c m}} & \text { for } & H>\rho_{p c m} \cdot \lambda
\end{array}\right.
$$

275 In equation (9) $\lambda$ is the latent heat of the PCM while $\rho_{\mathrm{pcm}}$ is the density of PCM. The thermophysical properties of PCM used in the current study are given in Table 1.

\begin{tabular}{|c|c|c|}
\hline \multicolumn{2}{|l|}{ Commercial Name } & Salt hydrate \\
\hline \multicolumn{2}{|l|}{ PCM category } & Inorganic \\
\hline \multicolumn{2}{|l|}{ Melting point (K) } & 389.85 \\
\hline \multicolumn{2}{|l|}{ Latent heat $(\mathrm{kJ} / \mathrm{kg})$} & 160 \\
\hline \multicolumn{2}{|l|}{ Length of PCM tube (m) } & 24 \\
\hline \multicolumn{2}{|l|}{ Diameter of PCM tube (m) } & 0.35 \\
\hline Thermal conductivity $\left(\mathrm{W} / \mathrm{m}^{2}-\mathrm{K}\right)$ & both phases & 0.7 \\
\hline Specific heat capacity $(\mathrm{kJ} / \mathrm{kg}-\mathrm{K})$ & both phases & 2.61 \\
\hline
\end{tabular}

Table 1: Thermo-Physical properties of PCM used for the current study [26] 
of the PCM with the difference in latent heat between a final and initial node of the PCM storage tank.

281

$$
Q_{s t, c}=M_{p c m}\left(\lambda_{\mathrm{mx}}-\lambda_{i n}\right)
$$

282

283

Power transferred to HTF by PCM during discharging mode is calculated by equation (11)

284

$$
P_{t r, d}=m_{H T F} C_{H T F}\left(T_{H T F, o}-T_{H T F, i}\right)
$$

285

\subsection{Validation of the Computational Model}

287

Currently used PCM computational model has been validated from the experimental results of Zivkovic et al. [33]. Results are presented for the melting case of the PCM. Zivkovic et al. [33] using $\mathrm{CaCl}_{2} \cdot 6 \mathrm{H}_{2} \mathrm{O}$ PCM encapsulated in the rectangular container made of stainless steel. The length and breadth of the container are both $100 \mathrm{~mm}$, while the thickness is $20 \mathrm{~mm}$, respectively. The container with solid PCM was placed in a bath having a constant temperature of $333.15 \mathrm{~K}$. The PCM container was well insulated on the lateral sides. The experimental results were reproduced through the current computational model. To reproduce the result the convective heat transfer coefficient between air and the container wall is determined by $\mathrm{h}_{\text {conv }}=16 \mathrm{~W} / \mathrm{m}^{2}-\mathrm{K}$ and $\mathrm{T}_{\infty}$ was $333.15 \mathrm{~K}$ [33]. Thermophysical properties of the $\mathrm{CaCl}_{2}$. $6 \mathrm{H}_{2} \mathrm{O}$ are tabulated in Table 2 .

\begin{tabular}{|c|c|c|}
\hline \multicolumn{2}{|l|}{ Melting Point (K) } & 303.05 \\
\hline \multicolumn{2}{|l|}{ Latent heat $(\mathrm{kJ} / \mathrm{kg})$} & 187 \\
\hline \multirow{2}{*}{ Density $\left(\mathrm{kg} / \mathrm{m}^{3}\right)$} & Solid & 1710 \\
\hline & Liquid & 1530 \\
\hline \multirow{2}{*}{ Thermal conductivity $\left(\mathrm{W} / \mathrm{m}^{2}-K\right)$} & Solid & 1.09 \\
\hline & Liquid & 0.53 \\
\hline \multirow{2}{*}{ Specific heat capacity $(\mathrm{kJ} / \mathrm{kg}-K)$} & Solid & 1.4 \\
\hline & Liquid & 2.2 \\
\hline
\end{tabular}

Table 2: Thermo-Physical properties of $\mathrm{CaCl2}$. $6 \mathrm{H} 2 \mathrm{O}$

A comparison between the experimental results from Zivkovic et al. [33] and the current computational model, for the PCM temperature at the center of the container, is presented in Figure 5. 


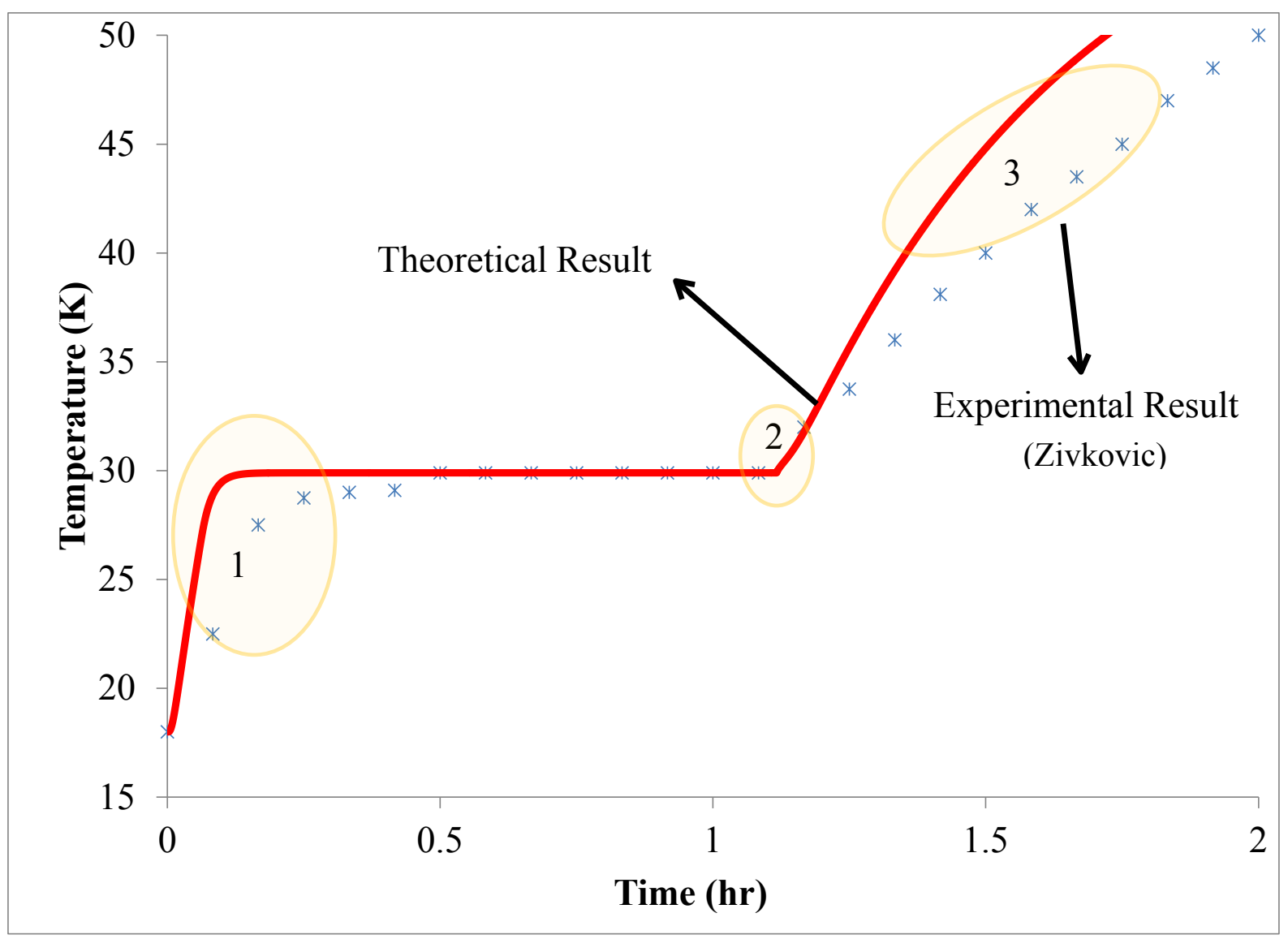

Figure 5: Comparison of the PCM modeling results with the experimental results of Zivkovic and Fujii [33] for the melting of PCM.

It has been observed from Figure 5 that agreement is well within the uncertainties indicated by Zivkovic et al. [33]. Three major observations and discrepancies (mentioned in Figure 5) between the predicted results and the experimental results are observed that are explained below:

1. In the beginning, sensible heat released by the PCM was predicted faster compared to the experimental result. This is mainly due to the assumption considered in the theoretical model which neglects the conduction between the container wall and PCM. This point is indicated as $1 \mathrm{in}$ Figure $\underline{5}$.

2. Calculated PCM melting time is observed slightly higher compared to the experimental result which is mainly due to the reason that the natural convection currents within the PCM are not incorporated in the theoretical model. This point is indicated as 2 in Figure 5.

3. The theoretical model predicted the higher temperature in the liquid region compared to the experimental results at any time. This discrepancy is indicated as 3 in Figure 5. This mainly due to the reasons indicated by Zivkovic et al. [33] that the calculated heat transfer coefficient is a little bit higher compared to the real one.

Therefore it can be assumed very carefully that avoiding the natural convection and thermal conduction of the container wall at this stage may not produce a significant error in the prediction of the PCM 
temperature.

321

322

323

Properties of the working fluid R245fa are shown in Table 4.

\begin{tabular}{|l|l|}
\hline Working fluid & R245fa \\
\hline Critical temperature & $154.01^{\circ} \mathrm{C}$ \\
\hline Critical pressure & $3.651 \mathrm{MPa}$ \\
\hline ODP & 0 \\
\hline Net GWP & 4 \\
\hline Flammability & High \\
\hline
\end{tabular}

327 The power generated by the expander is calculated by equation (12).

$$
W_{t}=m_{w f}\left(h_{t, i}-h_{t, o}\right)
$$

The total power consumed by the pump is computed by equation (13) and (14) for ISOS and DSOS respectively.

$$
W_{p}=W_{p 1}+W_{p 2}
$$

There is only one pump used in DSOS. Therefore, pump power is given by equation (14)

$$
W_{p}=W_{p 1}
$$


Pump power within the ORC cycle is calculated by enthalpy difference across the organic fluid pump.

$$
W_{p 1}=m_{w f}\left(h_{p, o}-h_{p, i}\right)
$$

333

335

336

340

Where os represents the isentropic process. The energy required in the heating process of the ORC is 346

However, in the case of ISOS, the power consumed by the pump in the solar loop is calculated by equation (16) using a fixed value of $65 \%$ for solar pump efficiency $\varepsilon_{s p}$.

$$
W_{p 2}=\frac{m_{H T F} \Delta P}{\varepsilon_{s p} \rho_{H T F}}
$$

The pressure drop $\Delta P$ comprises the pressure loss in the system's pipe network $\Delta P_{L}$ and the pressure loss across the solar collector array $\Delta P_{c l}$. The total length of the pipe network is assumed to be $200 \mathrm{~m}$ and diameter $20 \mathrm{~mm}$. The Darcy friction factor $f$ associated with pressure drop is computed according to correlations based on the Reynolds number given in Incropera et al. [40]

$$
\begin{gathered}
f=0.316 \mathrm{Re}^{-1 / 4} ; \quad \operatorname{Re}<2 \times 10^{4} ; \\
f=0.814 \mathrm{Re}^{-1 / 5} ; \quad \operatorname{Re} \geq 2 \times 10^{4} ; \\
\frac{\Delta P_{L}}{L}=\frac{8 m_{H T F}^{2} f}{\pi^{2} \rho_{H T F} D^{5}}
\end{gathered}
$$

The pressure drop across the solar collector array is calculated by an empirical correlation given by Freeman et al. [18].

$$
\Delta P_{c l}=A_{c l}\left(21.77 m_{H T F}^{2}+3.54 m_{H T F}\right)
$$

The isentropic efficiency of the expander and the pump is defined by equation (21) and (22)

$$
\varepsilon_{t}=\frac{h_{t, i}-h_{t, o}}{h_{t, i}-h_{t, o s}}
$$

$$
\varepsilon_{p}=\frac{h_{p, o s}-h_{p, i}}{h_{p, o}-h_{p, i}}
$$

calculated by the enthalpy increment of the organic fluid from the pump to the expander.

$$
W_{n e t}=W_{t} \varepsilon_{g}-W_{p}
$$




$$
Q_{O R C}=m_{w f}\left(h_{t, i}-h_{p, o}\right)
$$

349 The ORC efficiency for both configurations is defined by the ratio of the net power output to the heat

350 supplied [6].

$$
\eta_{O R C}=\frac{W_{n e t}}{Q_{O R C}}
$$

351

The system efficiency of both solar ORC systems is expressed by

$$
\eta_{s y s}=\eta_{O R C} \cdot \eta_{c l}
$$

The increment in a capacity factor of both configurations is calculated by a relative increment in working hours by use of PCM storage.

$$
C F_{i n c}=\frac{W h_{\mathrm{w}, \mathrm{pcm}}-W h_{w o, p c m}}{W h_{\mathrm{w}, \mathrm{pcm}}}
$$

\section{Results and Discussions}

Results obtained from dynamic MATLAB simulation of solar ORC systems are presented, analyzed and discussed in this section. A time step of 1 hour is selected for the whole simulation process. Islamabad is chosen as a reference location having coordinates: $33.7294^{\circ} \mathrm{N}, 73.0931^{\circ} \mathrm{E}$. Whole year simulations are carried out to compare the performances of both DSOS and ISOS. Firstly, dynamic simulations are carried out for the coldest and hottest weeks of the year. The performance of PCM storage is also compared for both DSOS and ISOS during charging and discharging mode.

Results of system efficiencies of both configurations and net power output are also compared and discussed. Secondly, the performance of both configurations is compared for the whole year. Moreover, it is also analyzed how much heat is stored by PCM during charging mode and how much power is delivered to the PCM by HTF in discharging mode. Finally, an increase in the capacity factor by using PCM storage for both configurations are presented and analyzed.

\subsection{Performance of the hottest week}

\subsubsection{Variation in temperature profiles of HTF and PCM during charging mode}

During charging mode, hourly average daily temperature profiles of both PCM and HTF for ISOS and DSOS during the hottest week ( $2^{\text {nd }}$ week of June) of the year are shown in Figure 6 and Figure 7 respectively. It can be seen that HTF temperature shows an increasing and decreasing trend with respect to the rise and fall of solar radiation. However, it remains constant initially with an initial decrement in solar radiation. By comparing Figure 6 and Figure 7, it is observed that the number of charging hours for ISOS and DSOS is found to be 9 and 7 hours, respectively. The number of charging hours is higher for ISOS because, within the selected range of parametric conditions, HTF temperature cannot reach 
up to the imposed limit of $390 \mathrm{~K}$. Increment in temperature of PCM for ISOS and DSOS is observed to be $7.7 \mathrm{~K}$ and $18.5 \mathrm{~K}$, respectively. However, in the case of HTF, these values are found to be $14.8 \mathrm{~K}$ and $18 \mathrm{~K}$. Moreover, at maximum HTF temperature, the temperature difference between HTF and PCM is found to be $10 \mathrm{~K}$ and $0 \mathrm{~K}$ for ISOS and DSOS, respectively. Hence, it shows that heat transfer between HTF and PCM is higher for DSOS in comparison with ISOS. Conclusively, in case of DSOS, there is a steep rise in temperature of HTF until it reaches up to the melting point of the PCM under selected operating and boundary conditions. Conversely, in case of ISOS, HTF temperature doesn't reach up to that limit. This can happen because water has 2.5 times higher value of specific heat capacity as compared to R245fa within the given temperature range.

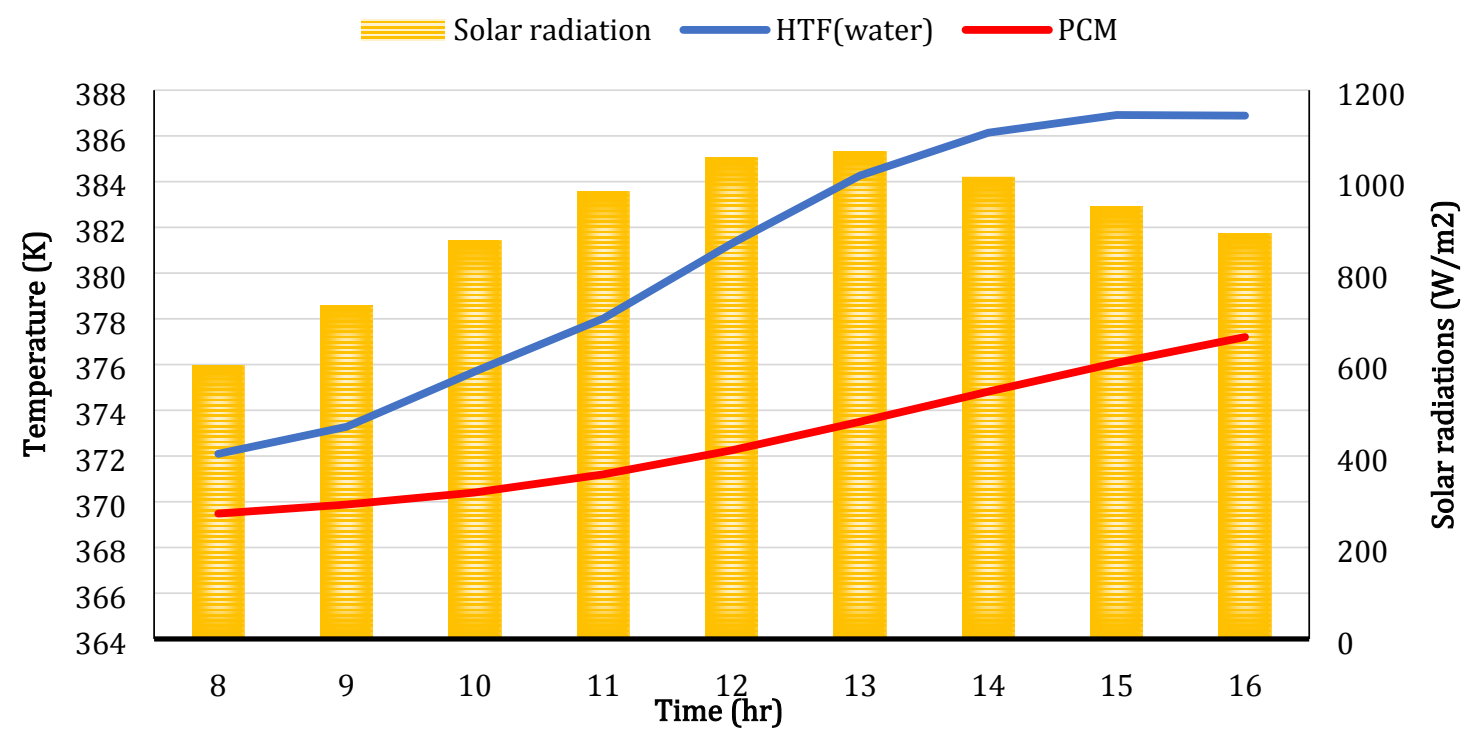

Figure 6: Variation in temperature profiles of HTF and PCM with solar radiation for ISOS during charging mode in the hottest week

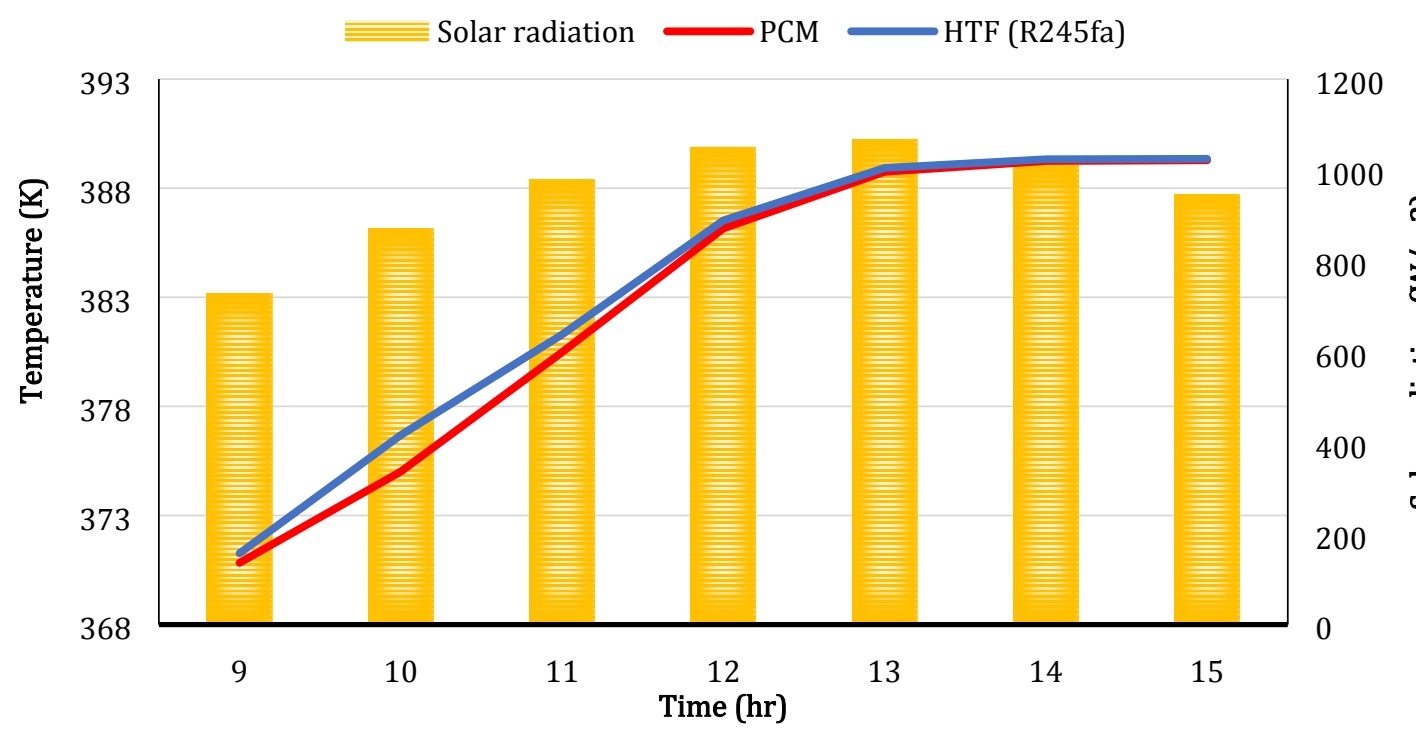

Figure 7: Variation in temperature profiles of HTF and PCM with solar radiation for DSOS during 


\subsubsection{Variation in temperature profiles of HTF and PCM during discharging mode}

A numerical simulation model of the PCM storage tank is developed using MATLAB. The finite difference method is used to discretize time and space (along one dimension). Therefore, the length of the PCM storage tank is divided into 105 equally spaced nodes. The simulation time step is selected to be 1 hour. The model has calculated the temperature of PCM and HTF at each node for every hour during the whole simulation process. Figure 8 and Figure 9 show variation in hourly average weekly temperature of PCM and HTF in the hottest week of the year during discharging mode for ISOS and DSOS respectively. It is observed that the temperature of PCM and HTF generally increases along the length of the heat storage tank for both ISOS and DSOS. This might happens because the temperature difference between PCM and HTF is large at the initial node. Therefore, heat transfer from PCM to HTF is very high at the beginning of discharging process.

Therefore, the drop in PCM temperature is larger at that point. Conversely, there is the least temperature difference between HTF and PCM at the final node. Therefore, heat transfer between HTF and PCM is comparatively lesser at the final node. Therefore, the drop in PCM temperature is lesser at that point. Moreover, the temperature difference between a final and initial node of PCM is found to be $14.01 \mathrm{~K}$ and $1.19 \mathrm{~K}$ for DSOS and ISOS respectively. Furthermore, an increase in the temperature of HTF along the PCM storage tank for DSOS is found 7.4 times higher than ISOS. This might happen due to the higher heat capacity of water as compared to R245fa. However, the relative increment in PCM temperature with respect HTF decreases along the length of the PCM storage tank.

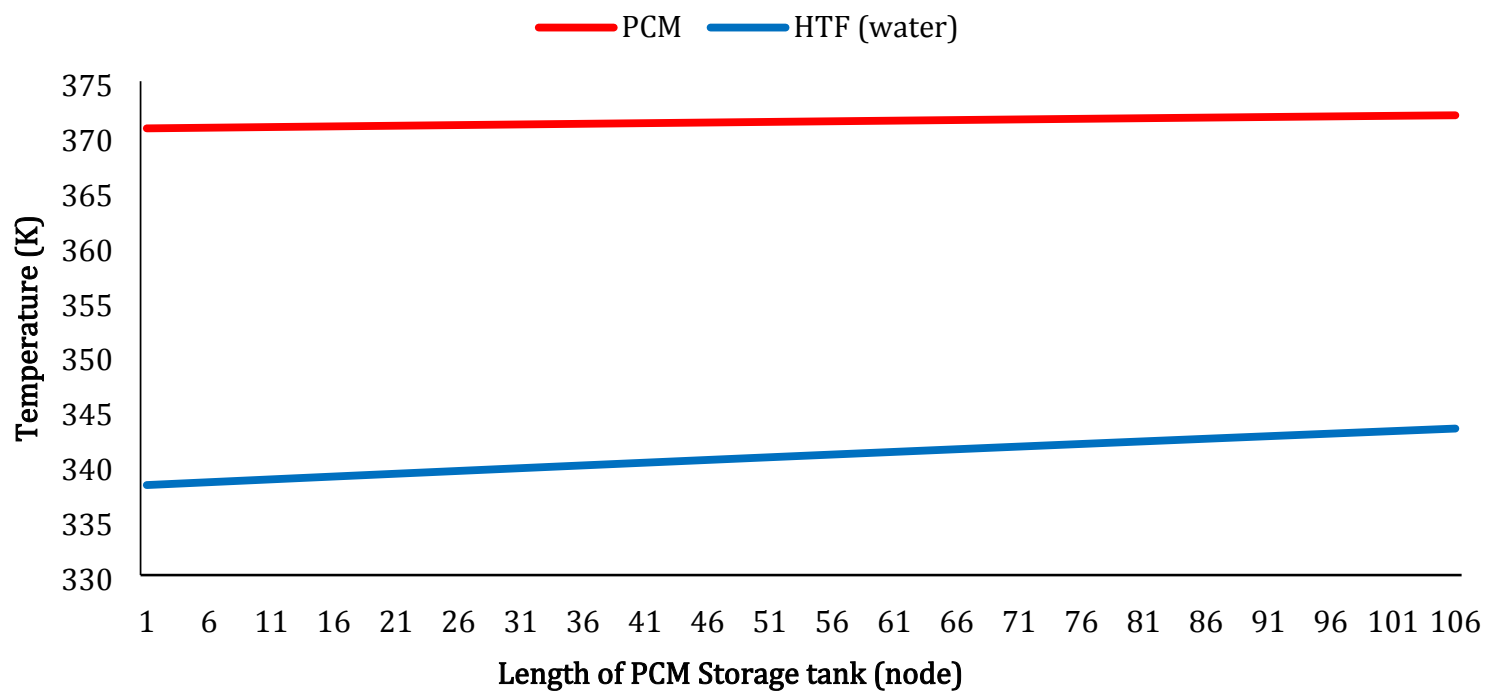

Figure 8: Variation in temperature of PCM \& HTF during discharging mode for ISOS in the hottest week 


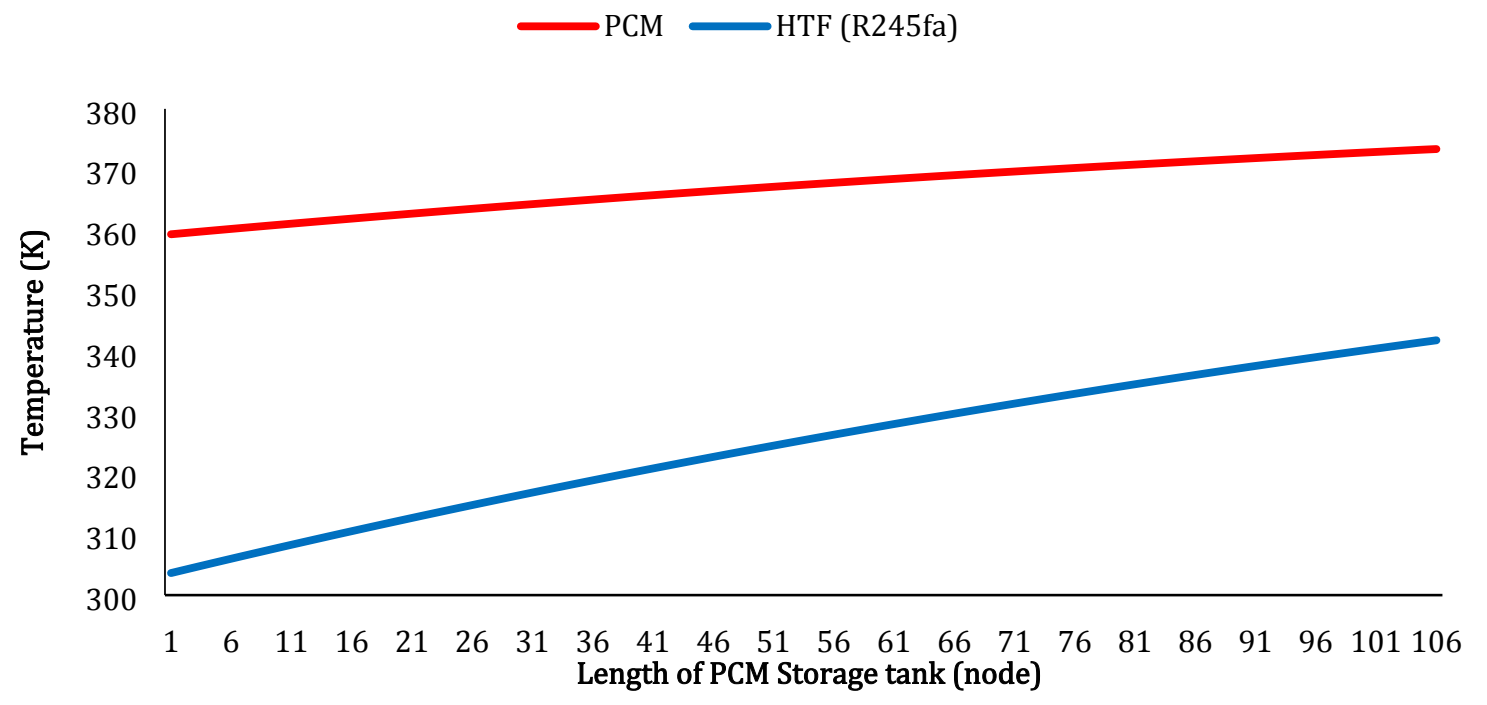

412

413 Figure 9: Variation in temperature of PCM \& HTF during discharging mode for DSOS in the hottest week

$414 \quad 4.1 .3 \quad$ Variation in system efficiencies and net power output

415 System efficiency and net power output are the two major parameters that generally describe the

416 performance of thermal systems. Therefore, these parameters are calculated for both ISOS and DSOS.

417 Figure 10 depicts the results for hourly average daily system efficiency and net power output of ISOS

418 and DSOS during the hottest week of the year. In the case of DSOS, the system works from 8:00 till

419 21:00 hours, however, for ISOS it works between 7:00 to 20:00. DSOS has resulted in an extra working

420 hour than ISOS on an average daily basis. The reduction in working hours for ISOS is due to the weaker

421 thermal match between HTF and PCM as shown in Figure 6 and Figure 8. The system efficiency and

422 the net power output for DSOS are found to be 5\% and 2.4 times higher than ISOS respectively. The

423 maximum values of the aforementioned parameters are found at the time instant of 15:00 hours. It

424 happens due to the maximum charging of the PCM storage, which occurs at this time instant, as shown

425 in Figure 6 and Figure 7. Further, DSOS has achieved 7.5\% higher system efficiency and $6.5 \mathrm{~kW}$ extra

426 power than ISOS on an average daily basis. Hence, DSOS has demonstrated better thermal performance

427 in comparison with ISOS.

428 This might be because of two major reasons: firstly, higher thermal losses occur across evaporator in

429 ISOS (research has shown that more than $50 \%$ of exergy losses occur in the evaporator section [18]).

430 Secondly, extra power is required to operate the solar pump. 


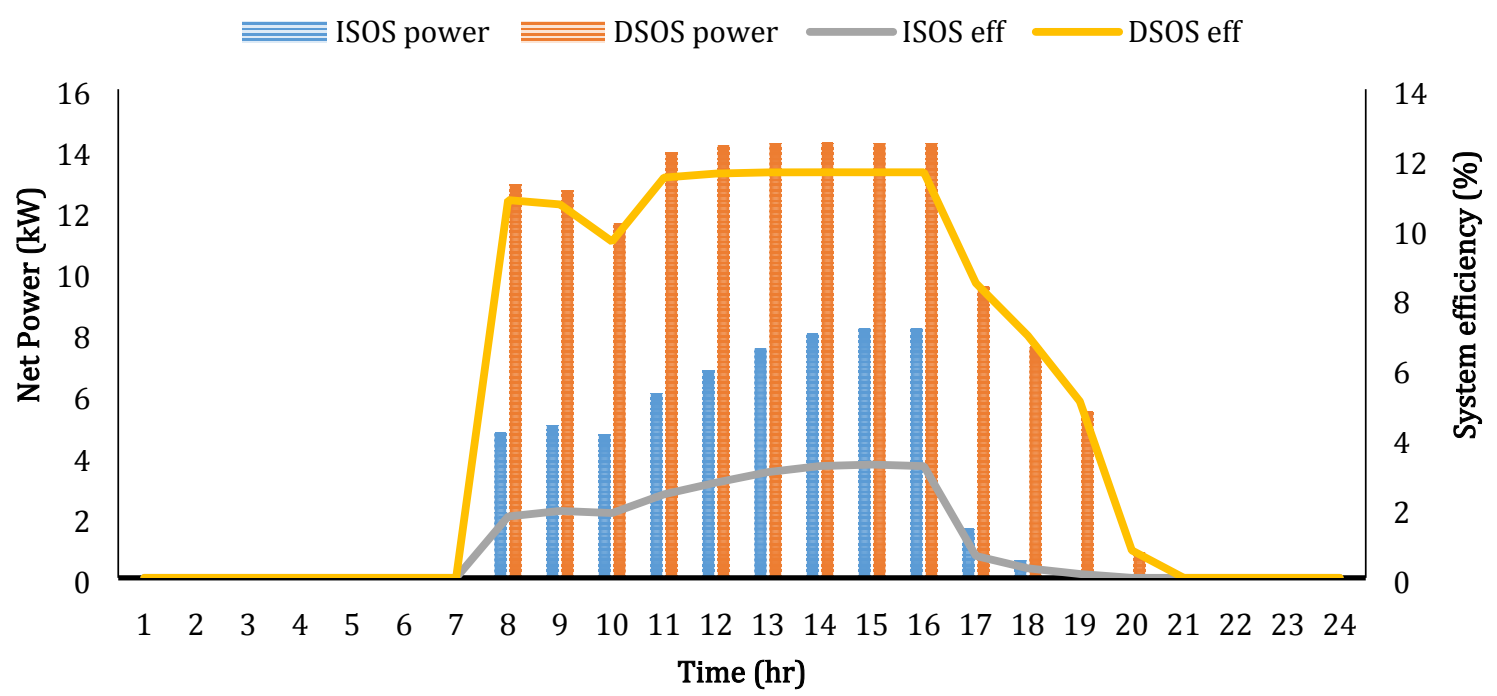

432

Figure 10: Variation in system efficiencies and net power output of DSOS and ISOS during the hottest week

\subsection{Performance of the coldest week}

\subsubsection{Variation in system efficiencies and net power output}

Figure 11 shows that the hourly average daily system efficiencies and net power output for ISOS and DSOS during the coldest week of the year ( $1^{\text {st }}$ week of January). There are weak solar radiation and very low ambient temperature during the coldest week. Both of the systems work between 11:00 to 15:00. Hence, these weather conditions are not enough to rise the HTF temperature at the outlet of the storage tank up to the designed value of $370 \mathrm{~K}$. Therefore, the charging process does not take place in both systems. However, both systems have demonstrated an identical trend with the hottest week. DSOS has shown higher 4.5 times system efficiency and 1.4 times larger net power output as compared to ISOS on an average daily basis. Moreover, DSOS has achieved $1.09 \%$ higher system efficiency and $0.32 \mathrm{~kW}$ extra power than ISOS on an average daily basis. Furthermore, both systems have shown maximum system efficiencies and net power at the time instant of 14:00 hour because largest solar radiation and highest ambient temperature occur at that time. 


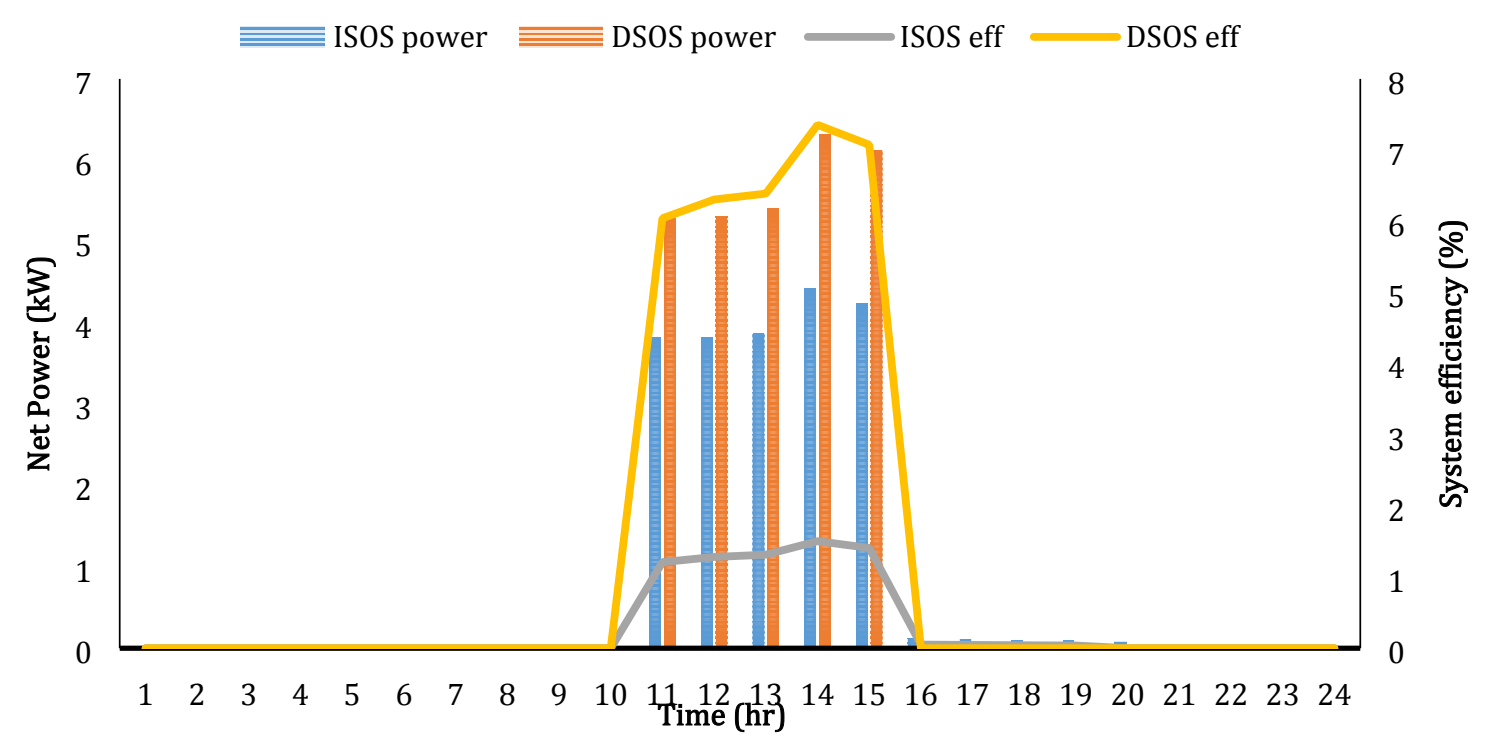

Figure 11: Variation in system efficiencies and net power output of DSOS and ISOS during the coldest week

\section{$451 \quad 4.3 \quad$ Performance over the month}

\subsubsection{Variation in system efficiencies and net power output}

453 Figure 12 shows the daily average monthly system efficiencies and net power output of ISOS and

454 DSOS, respectively. By comparing Figure 3 and Figure 12, it is observed that both parameters (system 455 efficiency and net power output) increase and decrease with rising and fall in solar radiation \& ambient 456 temperature. Therefore, both systems have followed similar behavior as seen in the case of weekly 457 simulation. The maximum value of system efficiencies and net power output are observed in June being 458 hottest month. Conversely, these values are found to be minimum in January that is the coldest month. 459 The average system efficiency achieved and daily average net power output delivered by ISOS on 460 annual basis is observed to be $1.71 \%$ and $34.02 \mathrm{~kW}$, respectively. While DSOS has shown 4.5 times 461 higher system efficiency and 2.8 times higher net power output on annual basis. Furthermore, DSOS 462 has shown $6.1 \%$ higher system efficiency and $61.5 \mathrm{~kW}$ higher average daily net power output than ISOS 463 on annual basis. Hence, DSOS has shown much better thermal performance than ISOS. 


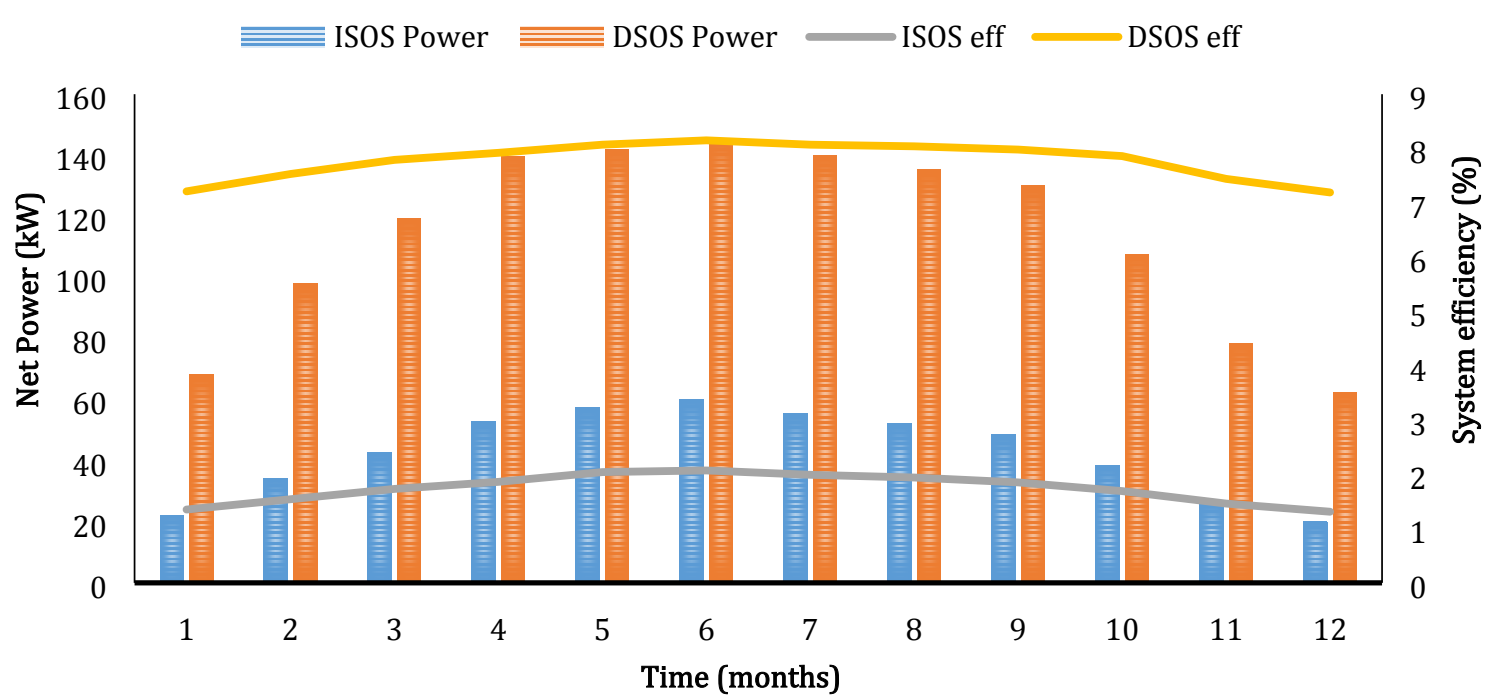

Figure 12: Variation in system efficiencies and net power output of DSOS and ISOS on daily average monthly basis

\section{$467 \quad 4.3 .2 \quad$ Heat stored by PCM during charging mode}

468 The daily average monthly amount of heat stored by the PCM storage tank during charging mode for

469 DSOS and ISOS is shown in Figure 13. The PCM storage system is designed to work at PCM melting 470 point temperature. However, in the current study, the total amount of heat stored by PCM is the sum of 471 both sensible and latent heat. It is observed that the amount of heat stored for both systems increase and 472 decrease with respect to rise and fall in solar radiation and ambient temperature as shown in Figure 3 473 and Figure 13. Moreover, maximum and minimum amount of heat stored by PCM is observed during 474 June and January, respectively. However, a larger amount of heat is stored by ISOS as compared to 475 DSOS. This can happen because the larger amount of heat transfer occurs across ISOS due to a higher 476 number of charging hours. The daily average amount of heat stored per annum by PCM storage for 477 ISOS is found to be 4.24 MJ more than DSOS. Furthermore, the maximum difference in the average 478 daily amount of heat stored for ISOS and DSOS is observed to be $23 \mathrm{MJ}$ that occurs in June. However, 479 minimum difference in daily average amount heat stored for both systems is found to be 6 MJ that 480 occurs in January. 


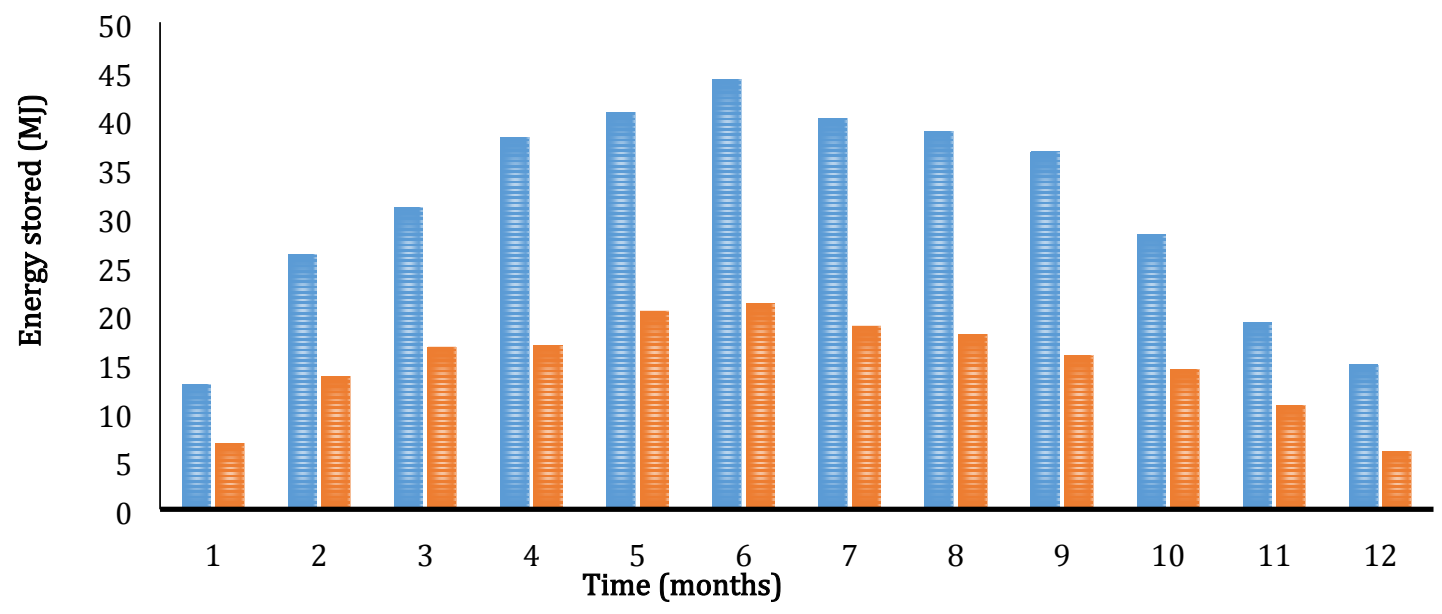

481

Figure 13: Variation in the amount of heat stored by PCM storage tank during charging mode for DSOS and ISOS on daily average monthly basis

\subsubsection{Power Transferred by PCM to HTF during discharging mode}

When solar radiation fall below the imposed limit $\left(400 \mathrm{~W} / \mathrm{m}^{2}\right)$, both systems undergo discharging mode. Power transferred to the HTF from PCM for both systems on a daily average monthly basis during discharging mode is shown in Figure 14. It is observed that the amount of power transferred by PCM to HTF for both systems increase and decrease with respect to rise and fall in solar radiation and ambient temperature as shown in Figure 3 and Figure 14. Furthermore, the maximum and minimum amount of power transferred by PCM is observed during June and January, respectively. However, a larger amount of power is transferred by PCM for ISOS as compared to DSOS. This might be because of the stronger thermal match between PCM and HTF for DSOS as compared to ISOS as shown in Figure 8 and Figure 9. Furthermore, the maximum difference in the amount of power transferred by PCM for ISOS and DSOS is observed in summer months.

However, a minimum difference in power transferred by PCM for both systems is found in the winter months. Furthermore, power transferred by PCM to HTF is 4.8 times higher for DSOS as compared to ISOS on an annual basis. 


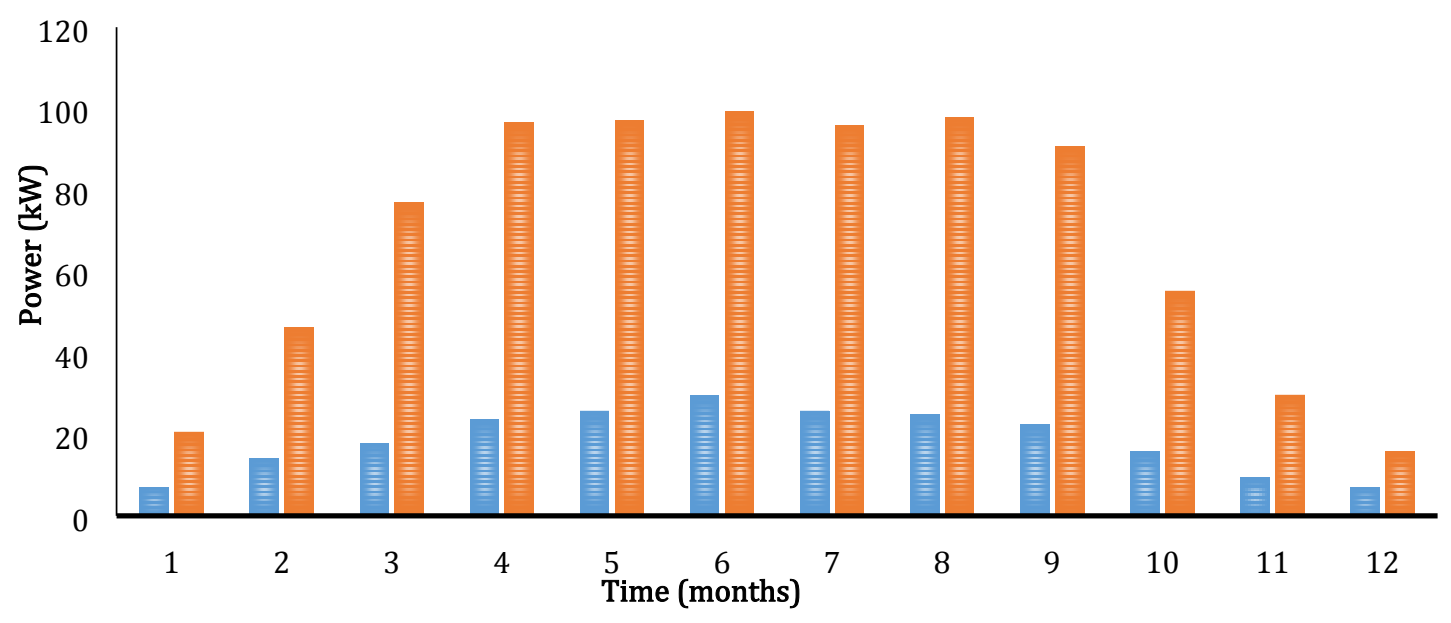

498

Figure 14: Variation in power transferred by PCM to HTF during discharging mode for DSOS and ISOS on daily average monthly basis

\subsubsection{Increment in capacity factor by employing PCM storage}

The capacity factor of both systems increases by employing PCM storage in the systems. Figure 15 compares the daily average monthly increment in capacity factor by using PCM storage for both systems. The increment in capacity factor usually depends upon the size of the heat storage unit as well as operating and boundary conditions. It is observed that it generally increases with increment in solar radiation and ambient temperature as shown in Figure 3 and Figure 15. However, in the case of DSOS, it has shown higher increment for the summer months having higher solar radiation and ambient temperature. Moreover, DSOS has shown higher increment in capacity factor as compared to ISOS. Furthermore, with PCM storage, the capacity factor is increased by $17 \%$ and $21.71 \%$ on annual basis for ISOS and DSOS respectively.

$$
\equiv \text { ISOS } \equiv \text { DSOS }
$$

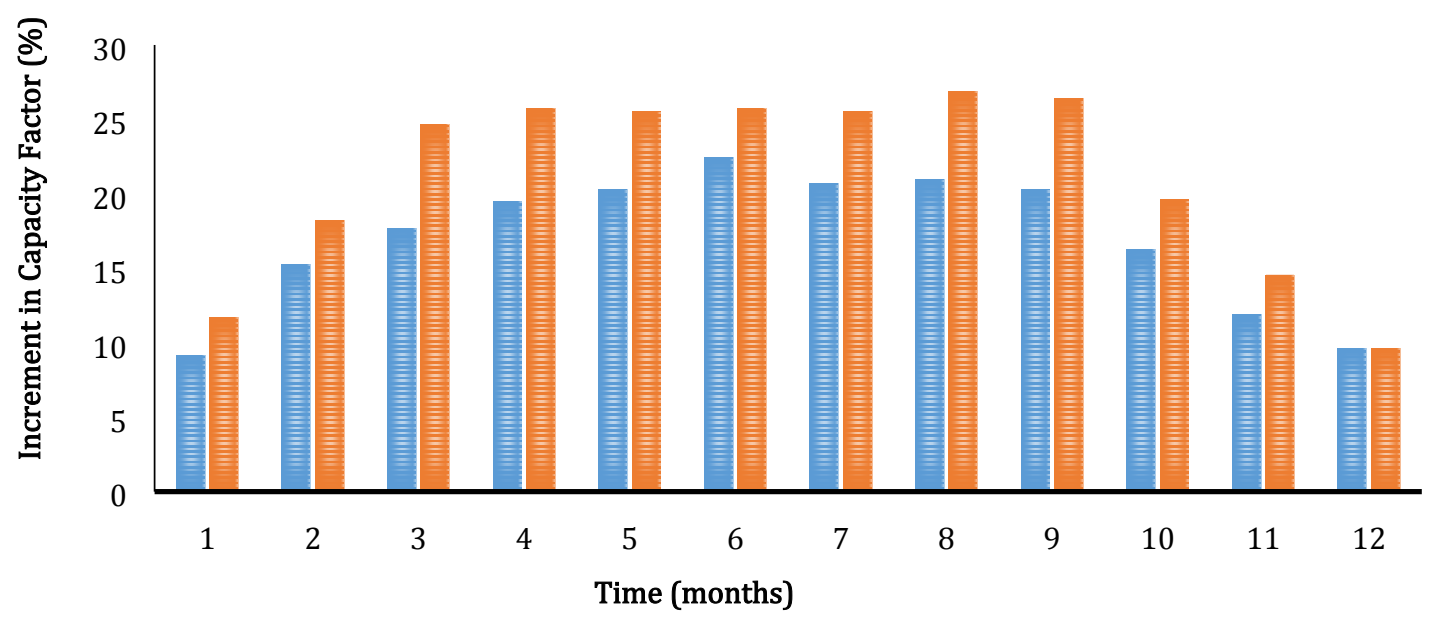


Figure 15: Variation in increment in Capacity Factor by using PCM storage for DSOS and ISOS on daily average monthly basis

\section{Conclusions}

The thermodynamic performance of DSOS and ISOS is compared in this study. A PCM storage tank is employed in both systems to increase the capacity factor and to assure the stability of power generation. A numerical mathematical model of PCM storage is developed. The model resulted in temperature profiles of HTF and PCM that varies with time. Annual dynamic simulations are carried out under timevarying conditions for both systems. It is concluded from results that DSOS has shown overall better thermal performance as compared to ISOS. The thermal match between HTF and PCM is stronger in the case of DSOS in comparison with ISOS. Hence, the temperature difference between HTF and PCM is found to be $0 \mathrm{~K}$ for DSOS and $10 \mathrm{~K}$ for ISOS at the maximum HTF temperature. Under given operating and boundary conditions, DSOS has shown $6.1 \%$ higher system efficiency and $61.5 \mathrm{~kW}$ higher daily average net power output than ISOS on an annual basis. Although the annual amount of heat stored by PCM for ISOS is 1.46 times higher than DSOS in charging mode. This happens might be due to specific heat capacity of water is almost 3 times higher than R245fa at selected operating and boundary conditions. However, during discharging mode, annual amount power transferred by PCM to HTF is 4.8 times higher for DSOS as compared to ISOS because of stronger thermal match of DSOS. Furthermore, DSOS has achieved 195 working hours higher than ISOS on annual basis. However, the performance of both systems can be improved significantly by applying more complex logical control. The future study involves the optimization of latent heat thermal energy storage systems for given constrains.

\section{Acknowledgment}

This research work has been supported by the National Natural Science Foundation of China (51806081), the Natural Science Foundation of Jiangsu Province (BK20180882), the China Postdoctoral Science Foundation (2018M632241) and the Open Foundation Program of Key Laboratory of Efficient Utilization of Low and Medium Grade Energy (Tianjin University), the Ministry of Education of China (201806-402).

\section{Nomenclature}

\section{Symbols}
A Area $\left[\mathrm{m}^{2}\right]$
a Heat transfer coefficient
C Specific heat $[\mathrm{J} / \mathrm{kg} / \mathrm{K}]$
CF Capacity factor 


\begin{tabular}{|c|c|c|}
\hline 547 & $\mathrm{D}$ & diameter $[\mathrm{m}]$ \\
\hline 548 & $\mathrm{~F}$ & Friction factor \\
\hline 549 & $\mathrm{H}$ & Volumetric enthalpy $\left[\mathrm{J} / \mathrm{m}^{3}\right]$ \\
\hline 550 & $\mathrm{~h}$ & Specific enthalpy $[\mathrm{kJ} / \mathrm{kg}]$ \\
\hline 551 & I & solar radiation $\left[\mathrm{W} / \mathrm{m}^{2}\right]$ \\
\hline 552 & $\mathrm{~m}$ & Mass flow rate $[\mathrm{kg} / \mathrm{s}]$ \\
\hline 553 & $\mathrm{~L}$ & Length $[\mathrm{m}]$ \\
\hline 554 & $\mathrm{M}$ & Mass $[\mathrm{kg}]$ \\
\hline 555 & $\mathrm{P}$ & Pressure [bar] \\
\hline 556 & Q & Heat transferred $[\mathrm{J}]$ \\
\hline 557 & $\mathrm{q}$ & Energy stored [J] \\
\hline 558 & $\mathrm{R}$ & Reynolds number \\
\hline 559 & $\mathrm{~T}$ & Temperature $[\mathrm{K}]$ \\
\hline 560 & $\mathrm{~W}$ & Work $[\mathrm{J}]$ \\
\hline 561 & \multicolumn{2}{|c|}{ Abbreviations } \\
\hline 562 & $\mathrm{P}$ & Pump \\
\hline 563 & $\mathrm{~V}$ & Valve \\
\hline 564 & CHP & Combined heat and power \\
\hline 565 & $\mathrm{CPC}$ & Compound parabolic concentrator \\
\hline 566 & CSP & Concentrated solar power \\
\hline 567 & DSOS & Direct solar organic Rankine cycle system \\
\hline 568 & DSG & Direct steam generation \\
\hline 569 & DVG & Direct vapor generation \\
\hline 570 & EFPC & Evacuated flat plate collector \\
\hline 571 & GWP & Global warming potential \\
\hline 572 & HTF & Heat transfer fluid \\
\hline 573 & ISOS & Indirect solar organic Rankine cycle system \\
\hline 574 & LHS & Latent Heat Storages \\
\hline 575 & ODP & Ozone depletion potential \\
\hline 576 & ORC & Organic Rankine cycle \\
\hline 577 & PCM & Phase change material \\
\hline 578 & RMB & Ren Min Bi \\
\hline 579 & SCHP & Scale distributed solar combined heat and power \\
\hline 580 & SEGS & Solar electricity generation system \\
\hline 581 & SHS & Sensible heat storage \\
\hline 582 & TMY & Typical meteorological year \\
\hline 583 & UK & United Kingdom \\
\hline 584 & \multicolumn{2}{|c|}{ Subscript } \\
\hline 585 & $\mathrm{amb}$ & Ambient \\
\hline 586 & $\mathrm{cl}$ & Collector \\
\hline 587 & $\mathrm{~g}$ & Generator \\
\hline 588 & $\mathrm{i}$ & Inlet \\
\hline 589 & $\mathrm{mx}$ & Maximum \\
\hline 590 & $\mathrm{~m}$ & melting point \\
\hline 591 & HTF & Heat transfer fluid \\
\hline 592 & ORC & Organic Rankine cycle \\
\hline 593 & o & outlet \\
\hline 594 & os & The isentropic process \\
\hline 595 & $\mathrm{p}$ & Pump \\
\hline 596 & PCM & Phase change material \\
\hline 597 & $\mathrm{sp}$ & Solar pump \\
\hline 598 & $\mathrm{t}$ & Turbine \\
\hline 599 & th & thermal \\
\hline 600 & $\mathrm{w}$ & with \\
\hline
\end{tabular}




\begin{tabular}{lll}
601 & wo & without \\
602 & wf & Working fluid \\
603 & \multicolumn{2}{c}{ Greek letters } \\
604 & $\beta$ & Angle \\
605 & $\lambda$ & Latent heat $[\mathrm{J} / \mathrm{kg} / \mathrm{K}]$ \\
606 & $\Delta$ & Change \\
607 & $\rho$ & Density $\left[\mathrm{kg} / \mathrm{m}^{3}\right]$ \\
608 & $\varepsilon$ & Efficiency \\
609 & $\eta$ & Thermal efficiency \\
610 & &
\end{tabular}




\section{References}

612 [1] W.A. Hermann, Quantifying global exergy resources, Energy. 31 (2006) 1685-1702.

[2] B.F. Tchanche, G. Papadakis, G. Lambrinos, A. Frangoudakis, Fluid selection for a lowtemperature solar organic Rankine cycle, Appl. Therm. Eng. 29 (2009) 2468-2476. doi:10.1016/J.APPLTHERMALENG.2008.12.025.

[3] J. Wang, Z. Yan, P. Zhao, Y. Dai, Off-design performance analysis of a solar-powered organic Rankine cycle, Energy Convers. Manag. 80 (2014) 150-157. doi:10.1016/J.ENCONMAN.2014.01.032.

[4] S. Quoilin, M. Orosz, H. Hemond, V. Lemort, Performance and design optimization of a low-cost solar organic Rankine cycle for remote power generation, Sol. Energy. 85 (2011) 955-966. doi:10.1016/J.SOLENER.2011.02.010.

[5] Y.-L. He, D.-H. Mei, W.-Q. Tao, W.-W. Yang, H.-L. Liu, Simulation of the parabolic trough solar energy generation system with Organic Rankine Cycle, Appl. Energy. 97 (2012) 630-641. doi:10.1016/J.APENERGY.2012.02.047.

[6] J. Li, J.Z. Alvi, G. Pei, J. Ji, P. Li, H. Fu, Effect of working fluids on the performance of a novel direct vapor generation solar organic Rankine cycle system, Appl. Therm. Eng. 98 (2016) 786-797. doi:10.1016/j.applthermaleng.2015.12.146.

[7] X.D. Wang, L. Zhao, J.L. Wang, Experimental investigation on the low-temperature solar Rankine cycle system using R245fa, Energy Convers. Manag. 52 (2011) 946-952. doi:10.1016/j.enconman.2010.08.022.

[8] J.L. Wang, L. Zhao, X.D. Wang, An experimental study on the recuperative low temperature solar Rankine cycle using R245fa, Appl. Energy. 94 (2012) 34-40. doi:10.1016/j.apenergy.2012.01.019.

[9] X.B. Bu, H.S. Li, L.B. Wang, Performance analysis and working fluids selection of solar powered organic Rankine-vapor compression ice maker, Sol. Energy. 95 (2013) 271-278. doi:10.1016/j.solener.2013.06.024.

[10] X.D. Wang, L. Zhao, J.L. Wang, W.Z. Zhang, X.Z. Zhao, W. Wu, Performance evaluation of a low-temperature solar Rankine cycle system utilizing R245fa, Sol. Energy. 84 (2010) 353-364. doi:10.1016/j.solener.2009.11.004.

[11] Y. Tian, C.Y. Zhao, A review of solar collectors and thermal energy storage in solar thermal applications, Appl. Energy. 104 (2013) 538-553. doi:10.1016/J.APENERGY.2012.11.051.

[12] A. Sharma, V.V. Tyagi, C.R. Chen, D. Buddhi, Review on thermal energy storage with phase change materials and applications, Renew. Sustain. Energy Rev. 13 (2009) 318-345. doi:10.1016/J.RSER.2007.10.005.

[13] J.Z. Alvi, M. Imran, G. Pei, J. Li, G. Gao, J. Alvi, Thermodynamic comparison and dynamic simulation of direct and indirect solar organic Rankine cycle systems with PCM storage, Energy Procedia. 129 (2017) 716-723. doi:10.1016/j.egypro.2017.09.103.

[14] F. Agyenim, N. Hewitt, P. Eames, M. Smyth, A review of materials, heat transfer and phase change problem formulation for latent heat thermal energy storage systems (LHTESS), Renew. Sustain. Energy Rev. 14 (2010) 615-628. doi:10.1016/J.RSER.2009.10.015.

[15] S.M. Hasnain, Review on sustainable thermal energy storage technologies, Part I: heat storage materials and techniques, Energy Convers. Manag. 39 (1998) 1127-1138. doi:10.1016/S0196-8904(98)00025-9.

[16] D. Zhou, C.Y. Zhao, Y. Tian, Review on thermal energy storage with phase change materials (PCMs) in building applications, Appl. Energy. 92 (2012) 593-605. doi:10.1016/J.APENERGY.2011.08.025.

[17] S. Li, H. Ma, W. Li, Dynamic performance analysis of solar organic Rankine cycle with 
thermal energy storage, Appl. Therm. Eng. 129 (2018) 155-164. doi:10.1016/J.APPLTHERMALENG.2017.10.021.

[18] J. Freeman, K. Hellgardt, C.N. Markides, An assessment of solar-powered organic Rankine cycle systems for combined heating and power in UK domestic applications, Appl. Energy. 138 (2015) 605-620. doi:10.1016/j.apenergy.2014.10.035.

[19] M. Wang, J. Wang, Y. Zhao, P. Zhao, Y. Dai, Thermodynamic analysis and optimization of a solar-driven regenerative organic Rankine cycle (ORC) based on flat-plate solar collectors, Appl. Therm. Eng. 50 (2013) 816-825. doi:10.1016/j.applthermaleng.2012.08.013.

[20] A.M. Pantaleo, S.M. Camporeale, A. Miliozzi, V. Russo, N. Shah, C.N. Markides, Novel hybrid CSP-biomass CHP for flexible generation : Thermo-economic analysis and profitability assessment, Appl. Energy. 204 (2017) 994-1006. doi:10.1016/j.apenergy.2017.05.019.

[21] A.M. Pantaleo, S.M. Camporeale, A. Sorrentino, A. Miliozzi, N. Shah, C.N. Markides, V.A. A, Hybrid solar-biomass combined Brayton / organic Rankine-cycle plants integrated with thermal storage : Techno-economic feasibility in selected Mediterranean areas, Renew. Energy. (2018) 1-19. doi:10.1016/j.renene.2018.08.022.

[22] G. Pei, J. Li, J. Ji, Analysis of low temperature solar thermal electric generation using regenerative Organic Rankine Cycle, Appl. Therm. Eng. 30 (2010) 998-1004. doi:10.1016/j.applthermaleng.2010.01.011.

[23] P. Gang, L. Jing, J. Jie, Design and analysis of a novel low-temperature solar thermal electric system with two-stage collectors and heat storage units, Renew. Energy. (2011). doi:10.1016/j.renene.2011.02.008.

[24] J. Freeman, I. Guarracino, S.A. Kalogirou, C.N. Markides, A small-scale solar organic Rankine cycle combined heat and power system with integrated thermal energy storage, Appl. Therm. Eng. 127 (2017) 1543-1554. doi:10.1016/j.applthermaleng.2017.07.163.

[25] M. Iasiello, K. Braimakis, A. Andreozzi, S. Karellas, Thermal analysis of a Phase Change Material for a Solar Organic Rankine Cycle, J. Phys. Conf. Ser. 923 (2017) 012042. doi:10.1088/1742-6596/923/1/012042.

[26] G. Manfrida, R. Secchi, K. Stańczyk, Modelling and simulation of phase change material latent heat storages applied to a solar-powered Organic Rankine Cycle, Appl. Energy. 179 (2016) 378-388. doi:10.1016/j.apenergy.2016.06.135.

[27] S. Lakhani, A. Raul, S.K. Saha, Dynamic modelling of ORC-based solar thermal power plant integrated with multitube shell and tube latent heat thermal storage system, Appl. Therm. Eng. 123 (2017) 458-470. doi:10.1016/j.applthermaleng.2017.05.115.

[28] Meteonorm, Global Solar Radiation Database - METEONORM, (2015).

[29] H. Hajabdollahi, A. Ganjehkaviri, M.N. Mohd Jaafar, Thermo-economic optimization of RSORC (regenerative solar organic Rankine cycle) considering hourly analysis, Energy. 87 (2015) 361-368. doi:10.1016/j.energy.2015.04.113.

[30] F. Calise, M.D. D’Accadia, M. Vicidomini, M. Scarpellino, Design and simulation of a prototype of a small-scale solar CHP system based on evacuated flat-plate solar collectors and Organic Rankine Cycle, Energy Convers. Manag. 90 (2015) 347-363. doi:10.1016/j.enconman.2014.11.014.

[31] E. Günther, S. Hiebler, H. Mehling, R. Redlich, Enthalpy of Phase Change Materials as a Function of Temperature : Required Accuracy and Suitable Measurement Methods, Int J Thermophys. 30 (2009) 1257-1269. doi:10.1007/s10765-009-0641-z.

[32] F. Mechanics, G. Petrone, L. Cammarata, G. Cammarata, Numerical simulation of pcm melting process, in: 2012: pp. 469-474.

[33] B. Zivkovic, I. Fujii, An analysis of isothermal phase change of phase change material within rectangular and cylindrical containers, Sol. Energy. 70 (2001) 51-61.

[34] F. Calise, C. Capuozzo, A. Carotenuto, L. Vanoli, Thermoeconomic analysis and off-design 
performance of an organic Rankine cycle powered by medium-temperature heat sources, Sol. Energy. 103 (2013) 595-609. doi:10.1016/j.solener.2013.09.031.

[35] Y. Feng, T. Hung, Y. Zhang, B. Li, J. Yang, Y. Shi, Performance comparison of low-grade ORCs (organic Rankine cycles) using R245fa, pentane and their mixtures based on the thermoeconomic multi-objective optimization and decision makings, Energy. 93 (2015) 2018-2029. doi:10.1016/j.energy.2015.10.065.

[36] M. Imran, M. Usman, B.-S. Park, H.-J. Kim, D.-H. Lee, Multi-objective optimization of evaporator of organic Rankine cycle (ORC) for low temperature geothermal heat source, Appl. Therm. Eng. 80 (2015) 1-9. doi:10.1016/j.applthermaleng.2015.01.034.

[37] J. Li, P. Li, G. Pei, J.Z. Alvi, J. Ji, Analysis of a novel solar electricity generation system using cascade Rankine cycle and steam screw expander, Appl. Energy. 165 (2016) 627-638. doi:10.1016/j.apenergy.2015.12.087.

[38] M. Usman, M. Imran, Y. Yang, D.H. Lee, B.-S. Park, Thermo-economic comparison of aircooled and cooling tower based Organic Rankine Cycle (ORC) with R245fa and R1233zde as candidate working fluids for different geographical climate conditions, Energy. 123 (2017) 353-366. doi:https://doi.org/10.1016/j.energy.2017.01.134.

[39] J. Li, J.Z. Alvi, G. Pei, Y. Su, P. Li, G. Gao, J. Ji, Modelling of organic Rankine cycle efficiency with respect to the equivalent hot side temperature, Energy. 115 (2016) 668-683. doi:10.1016/j.energy.2016.09.049.

[40] F.P. Incropera, T.L. Bergman, A.S. Lavine, D.P. DeWitt, Fundamentals of Heat and Mass Transfer, 2011. 